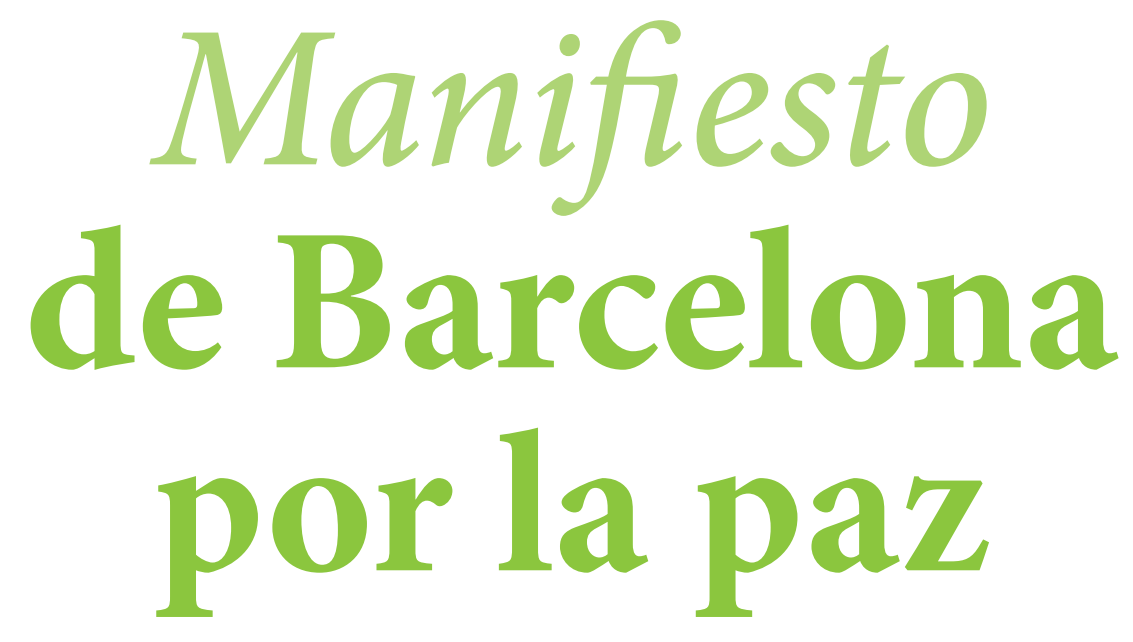

\begin{tabular}{|c|c|}
\hline \multirow[t]{4}{*}{ 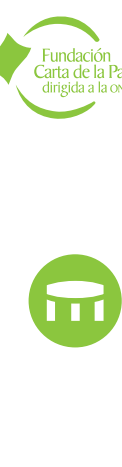 } & $\begin{array}{l}\text { Fundación } \\
\text { Carta de la Paz } \\
\text { dirigida a la ONU }\end{array}$ \\
\hline & www.cartadelapaz.org \\
\hline & $\begin{array}{l}\text { Congreso Internacional } \\
\text { Edificar la Paz } \\
\text { en el Siglo XXI }\end{array}$ \\
\hline & www.edificarlapaz.org \\
\hline & Universidad de Barcelona \\
\hline & www.ub.edu \\
\hline
\end{tabular}

Recibido: 15 de junio de 2012/Aprobado: 16 de junio de 2012. 


\section{Manifiesto de Barcelona por la paz}

Con motivo del Ier Congreso Internacional Edificar la Paz en el siglo XXI celebrado en Barcelona los días 23, 24 y 25 de abril del 2012, el Comité Científico, recogiendo las aportaciones, las comunicaciones y las ponencias que se han presentado y los trabajos precongresuales, da a conocer el siguiente Manifiesto. 


\section{Somos conscientes de:}

a. La difícil encrucijada en la que se halla la humanidad

b. La injusticia social que padecen millones de seres humanos

c. La intolerancia que provoca una multitud de víctimas

d. Las guerras que hieren el mundo

e. La fragilidad de la democracia

f. La devastación del medio ambiente

g. La indignación de muchas ciudadanas y ciudadanos

\section{Y manifestamos que:}

1. La paz no es un regalo; es un valor que se construye día a día.

2. El ser humano es capaz de hacer el mal, pero también el bien.

3. Cualquier persona está llamada a ser un agente de paz. La pacificación del mundo depende de todos. Nadie está exento de esta tarea.

4. Los acontecimientos del pasado han configurado nuestro presente.

5. No somos responsables de lo que acaeció en el pasado. Sin embargo, el futuro no está escrito. En gran parte, depende de nosotros.

6. La historia es una fuente de aprendizaje. Es un deber transmitirla con rigor y con la máxima objetividad. Rememorar el pasado constituye un deber.

7. No podemos olvidar a las víctimas del pasado. Su sufrimiento nos interpela y exige actuar de un modo eficiente y eficaz para evitar la reiteración del mal.

8. Las decisiones del presente afectan a los contemporáneos, pero también a las generaciones venideras. Somos responsables de edificar un mundo en paz, justo y fraterno y confiamos en el talento compartido y en la fuerza colectiva para conseguirlo.

9. La violencia genera más violencia. El verdadero antídoto a la violencia es la justicia y el ejercicio de la reconciliación. 
10. El desarme integral, material y espiritual, es condición ineludible para la paz.

11. Cualquier decisión en el ámbito local tiene sus efectos en el mundo global. Todo es interdependiente. Existe una solidaridad fundamental. Debemos tener consciencia de ello y potenciarla.

12. La diversidad es un bien necesario a proteger y amar. Todo ser humano tiene derecho a vivir en el marco de su(s) identidad(es), pero las identidades no son universos cerrados.

13. Lo que nos une es más profundo que lo que nos separa. No podemos perderlo de vista y tenemos que fomentar la fraternidad universal.

14. En la indignación hay un indicio de esperanza; pero el futuro requiere del compromiso libre de todas y todos.

15. La democracia, tal y como la conocemos, tiene que dar un salto cualitativo. La transparencia y la participación tienen que ser sus fundamentos.

16. La paz es el fruto de la libertad, la equidad y la solidaridad.

\section{Por ello, llamamos a:}

a. A todas las ciudadanas y ciudadanos, para que tomen consciencia que cada uno es un agente de paz y que la paz es la condición para la plenitud del ser humano.

b. A las instituciones educativas, formales y no formales, porque tienen la responsabilidad de educar en la cultura de paz y potenciar la resolución pacífica de conflictos.

c. A las universidades y a los centros de investigación, porque, junto con la sociedad civil organizada, busquen vías plausibles e inteligentes para pacificar el mundo.

d. A los medios de comunicación social, porque son la ventana del mundo. A través de ellos contemplamos la realidad. Tienen la gran responsabilidad de presentar lo que ocurre con fidelidad y rigor y promover la paz.

e. A los gobernantes, porque el mejor modo de construir el futuro es trabajar para el bien de los presentes. 